\title{
DAPK2 is a novel modulator of TRAIL-induced apoptosis
}

\author{
CR Schlegel ${ }^{1}$, A-V Fonseca ${ }^{1,2}$, S Stöcker ${ }^{1,3}$, ML Georgiou $^{1}$, MB Misterek ${ }^{1,4}$, CE Munro ${ }^{1}$, CR Carmo ${ }^{1,5}$, MJ Seckl ${ }^{1}$ \\ and AP Costa-Pereira*,1
}

Targeting molecules involved in TRAIL-mediated signalling has been hailed by many as a potential magic bullet to kill cancer cells efficiently, with little side effects on normal cells. Indeed, initial clinical trials showed that antibodies against TRAIL receptors, death receptor (DR)4 and DR5, are well tolerated by cancer patients. Despite efficacy issues in the clinical setting, novel approaches to trigger TRAIL-mediated apoptosis are being developed and its clinical potential is being reappraised. Unfortunately, as observed with other cancer therapies, many patients develop resistance to TRAIL-induced apoptosis and there is thus impetuous for identifying additional resistance mechanisms that may be targetable and usable in combination therapies. Here, we show that the death-associated protein kinase 2 (DAPK2) is a modulator of TRAIL signalling. Genetic ablation of DAPK2 using RNA interference causes phosphorylation of NF-KB and its transcriptional activity in several cancer cell lines. This then leads to the induction of a variety of NF- $\mathrm{KB}$ target genes, which include proapoptotic DR4 and DR5. DR4 and DR5 protein expression is correspondingly increased on the cell surface and this leads to the sensitisation of resistant cells to TRAILinduced killing, in a p53-independent manner. As DAPK2 is a kinase, it is imminently druggable, and our data thus offer a novel avenue to overcome TRAIL resistance in the clinic.

Cell Death and Differentiation (2014) 21, 1780-1791; doi:10.1038/cdd.2014.93; published online 11 July 2014

Despite the effort and resources invested in cancer research, cancer remains a serious public health problem. Most patients are treated surgically, with chemotherapeutic drugs and/or antibodies and small molecule inhibitors. Patients generally respond well to the initial therapy but frequently develop resistance to it. This poses a challenge to their treatment and calls for alternative approaches to be developed. Indeed, much excitement was generated in the mid-1990s when tumour necrosis factor (TNF)-related apoptosis-inducing ligand (TRAIL) was identified. ${ }^{1-4}$

TRAIL is a death receptor (DR) ligand that signals through DR4 and DR5, two members of the TNF receptor family. ${ }^{5-7}$ DR5 has two isoforms that differ by 29 amino acids and which are functionally indistinguishable. ${ }^{5,8}$ TRAIL ligation activates primarily the extrinsic apoptotic pathway. The formation of ligand/receptor complexes leads to the assembly of a multiprotein death-inducing signalling complex (DISC), which in the case of TRAIL is typically composed of the adaptor Fasassociated death domain, caspase-8, caspase-10 and/or
c-FLIP. These initiator caspases proteolytically cleave effector caspases such as caspase-3, caspase-6 and/or caspase-7 thereby activating them. This leads to the destruction of key cellular components and the appearance of typical features of apoptosis. TRAIL can also activate intrinsic apoptotic pathways via BID and thus involve mitochondria. By virtue of preferentially killing tumour cells, TRAIL is seen by many as a 'magic bullet' against cancer cells. Some cancer cells, however, are resistant, or develop resistance, to TRAIL-induced apoptosis. Several resistance mechanisms have been described but they do not account for all cases of resistant cells, ${ }^{9}$ suggesting that additional as yet unidentified mechanisms exist. Deregulation at receptor, DISC and mitochondria levels have all been described, and the involvement of mitogen-activated protein kinases and poly-(ADP-ribose) polymerase 1 (PARP1) have also been suggested. Here we show that death-associated protein kinase 2 (DAPK2) can be used as a target to overcome resistance to TRAIL-induced apoptosis.

${ }^{1}$ Department of Surgery and Cancer, Imperial College London, Faculty of Medicine, Hammersmith Hospital, Hammersmith Hospital Campus, ICTEM, Du Cane Road, London W12 ONN, UK

*Corresponding author: AP Costa-Pereira, Department of Surgery and Cancer, Imperial College London, Faculty of Medicine, Hammersmith Hospital, Hammersmith Hospital Campus, ICTEM, Du Cane Road, London W12 0NN, UK. Tel: +44 207594 2815; Fax: +44 203313 5830; E-mail: a.costa-pereira@ imperial.ac.uk

${ }^{2}$ Current address: Medical Research Council National Institute for Medical Research, The Ridgeway, London, UK

${ }^{3}$ Current address: German Cancer Research Center, Im Neuenheimer Feld 280, Heidelberg, Germany

${ }^{4}$ Current address: Otto-von-Guericke-University Magdeburg, Faculty of Process and Systems Engineering, Universitätsplatz 2, Magdeburg, Germany

${ }^{5}$ Current address: Instituto Gulbenkian de Ciência, Oeiras, Portugal

Abbreviations: BID, BH3 interacting-domain death agonist; DAPK, death-associated protein kinase; DcR, decoy receptor; DISC, death-inducing signalling complex; $\mathrm{DR}$, death receptor; FADD, Fas-associated death domain; FLIP, Fas-associated death domain-like interleukin-1 $\beta$-converting enzyme-like inhibitory protein; FITC, fluorescein isothiocyanide; $\mathrm{H}_{2} \mathrm{O}_{2}$, hydrogen peroxide; MAPK, mitogen-activated protein kinase; NF- $\kappa \mathrm{B}$, nuclear factor- $\kappa \mathrm{B}$; PARP, poly-(ADP-ribose) polymerase; $\mathrm{PE}$, phycoerythrin; qPCR, quantitative (real-time) polymerase chain reaction; qWB, quantitative western blot; REL, v-rel avian reticuloendotheliosis viral oncogene homolog; RIP, receptor interacting protein; RNAi, RNA interference; ROS, reactive oxygen species; SDS-PAGE, sodium dodecyl sulphate polyacrylamide gel electrophoresis; SEM, standard error of the mean; si, short interfering; siNS, non-targeting siRNA molecule; TNF, tumour necrosis factor; TRADD, tumor necrosis factor receptor type 1-associated DEATH domain protein; TRAIL, tumour necrosis factor-related apoptosis-inducing ligand; WB, western blot

Received 20.12.13; revised 27.5.14; accepted 28.5.14; Edited by A Villunger; published online 11.7.14 
DAPK2 (also known as DRP-1) belongs to the DAPK family, which comprises a number of serine/threonine kinases regulated by calcium/calmodulin that are involved in deathinducing pathways. The three main members (DAPK1-3) share a high degree of homology in the kinase domain but vary greatly outside this key region. The most studied protein is the founder molecule DAPK1, which has been implicated in interferon- $\gamma$, FAS ligand, TNF- $\alpha$ and ceramide-induced cell death, among others. ${ }^{10}$ The gene is often methylated in tumour cells and it is thought to be a tumour suppressor. ${ }^{11}$ DAPK2 is a much smaller protein than DAPK1 (42 versus $120 \mathrm{kDa}$ ), it lacks ankyrin repeats and, critically, the death domain (Supplementary Figure S1). Accordingly, evidence for a proapoptotic role is largely based on its ability to induce apoptosis-like cell morphology upon overexpression. ${ }^{12-14}$ We thus hypothesised that endogenous DAPK2 may under some circumstances have antiapoptotic properties and provide cancer cells with prosurvival cues.

\section{Results}

DAPK2 depletion sensitises resistant cells to TRAILmediated apoptosis. As DAPK2 lacks a recognisable death motif, we asked what the contribution of endogenous DAPK2 to cell death induced by different apoptotic triggers was. We used U2OS osteosarcoma cells and A549 non-small-cell lung cancer cells as examples of two cancer cell lines with different mutational backgrounds and which have been extensively characterised in our laboratory. ${ }^{15,16}$ RNA interference (RNAi) was used to modulate the levels of DAPK2 in these cells. A pool of short interfering (si) oligonucleotides targeting different regions of DAPK2 (henceforth, siDAPK2), which were validated by deconvolution (Supplementary Figure S2), efficiently reduced DAPK2 mRNA and protein levels in U2OS (Figure 1a) and A549 (Figure 1g) cells. Cells were transfected with siDAPK2, challenged with TRAIL (Figures $1 \mathrm{~b}$ and $\mathrm{h}$ ), cisplatin (Figures $1 \mathrm{c}$ and $\mathrm{i}$ ), hydrogen peroxide $\left(\mathrm{H}_{2} \mathrm{O}_{2}\right)$ (Figures 1d and j), TNF- $\alpha$ (Figures 1e and $\mathrm{k}$ ), taxol or etoposide (not shown), and cell death levels assessed using crystal violet viability assays. Cells transfected with a non-targeting siRNA pool (siNS) were used as controls in all experiments. The susceptibility of cells with near-to-none DAPK2 expression was compared with that of control cells. Data from three independent experiments (each with triplicate samples) are shown as the mean percentage of live cells \pm S.E.M. (Figure 1). U2OS were readily killed by cisplatin (Figure 1c), oxidative stress (Figure 1d), etoposide and taxol (not shown), and this was not dependent on DAPK2. A549 were less susceptible than U2OS to the killing effects of cisplatin (Figure 1i) or $\mathrm{H}_{2} \mathrm{O}_{2}$ (Figure 1j), but, as for U2OS cells, the induction of apoptosis was also independent of DAPK2 expression levels. As many other tumour cells, U2OS and A549, were resistant to DR-mediated cell death induced by TRAIL (Figures $1 \mathrm{~b}$ and $\mathrm{h}$, black bars) or TNF- $\alpha$ (Figures 1e and k). Both cell types could be sensitised to TNF- $\alpha$-induced death by inhibiting protein synthesis using cycloheximide (CHX) (not shown), but sensitisation to TNF- $\alpha$ was not achieved by silencing DAPK2 (Figures 1e and k). In contrast, reducing the levels of DAPK2 significantly sensitised U2OS and A549 cells to TRAIL-induced cell death
(Figures $1 \mathrm{~b}$ and $\mathrm{h}$, green bars), suggesting that DAPK2 functioned as an inhibitory molecule that modulated TRAIL signalling. Cell death was also assessed by measuring DNA hypoploidy (Supplementary Figure S3), which yielded similar results to those shown in Figures $1 b$ and $h$.

Downregulation of DAPK2 leads to sensitisation to TRAIL-induced apoptosis via increased apoptotic signalling. Having observed that U2OS and A549 cells were more susceptible to TRAIL-induced cell death after DAPK2 knockdown, we asked what the molecular consequences of DAPK2 silencing were. Cells were transfected as before, treated with TRAIL for varying periods of time, and proteins extracted and separated by sodium dodecyl sulphate (SDS)-polyacrylamide gel electrophoresis (PAGE) (Figures $1 \mathrm{f}$ and I). Western blot (WB) membranes were subsequently probed with antibodies specific to molecules activated downstream of TRAIL. TRAIL-induced apoptosis was studied over a period of 1-24 h and we chose to focus on earlier time points as caspase activation is generally a rapid event in cells sensitive to TRAIL. Caspase- 8 and -10 are two initiator caspases downstream of DRs and were thus analysed first. Caspase activation was faster and stronger in siDAPK2-transfected cells than in control cells (siNS) (Figures $1 \mathrm{f}$ and I), as seen by both the emergence of smaller caspase fragments $(43,41$ and $18 \mathrm{kDa})$ and also by the reduction in the full-length $55 \mathrm{kDa}$ protein. Indeed, caspase- 8 cleavage $1 \mathrm{~h}$ after TRAIL treatment was much weaker in siNS-transfected cells than in cells transfected with siDAPK2. The same was observed for caspase-10 (not shown). Activation of caspase-8 leads to activation of the effector caspase-3 and subsequent degradation of molecules such as PARP, which ultimately results in cellular demise. Accordingly, DAPK2 silencing also resulted in increased caspase-3 and PARP cleavage (Figures $1 \mathrm{f}$ and I). In addition, the reduction of BID expression and increased caspase- 9 cleavage after DAPK2 silencing indicated the recruitment of the intrinsic apoptotic pathway (Figures $1 \mathrm{f}$ and I). Collectively, these data suggest that DAPK2 inhibited caspase activation downstream of TRAIL by interfering both with the extrinsic and intrinsic apoptosis pathways.

DAPK2 silencing leads to the upregulation of DR5, a key receptor for TRAIL-induced apoptosis. The evidence for the involvement of both these pathways suggested that DAPK2 affected an upstream event common to both arms of TRAIL apoptotic pathways. Accordingly, transfection of U2OS and A549 cells with siDAPK2 led to the upregulation of DR5 (Figures $2 a-d$ ), one of the receptors through which TRAIL can signal to kill. DR4 was not expressed in U2OS cells (not shown) but it was expressed in A549 and its expression was also increased after silencing DAPK2 (Figure 2e). The greatly enhanced expression of DR4 and DR5 was analysed both by SDS-PAGE/quantitative WB (qWB) (Figures $2 a$ and $c$ ) and by flow cytometry (Figures $2 b, d$ and e). Silencing DAPK2 had no effect on the mRNA levels of any of the three TRAIL decoy receptors: DcR1 (TRAIL-R3/TRID/TNFRSF10C), ${ }^{17}$ DcR2 (TRAIL-R4/TRUNDD/TNFRSF10D) ${ }^{17}$ and osteoprotegerin $(\mathrm{OPG} / \mathrm{TNFSF} 11)^{18}$ (not shown). Interestingly, it also 
a

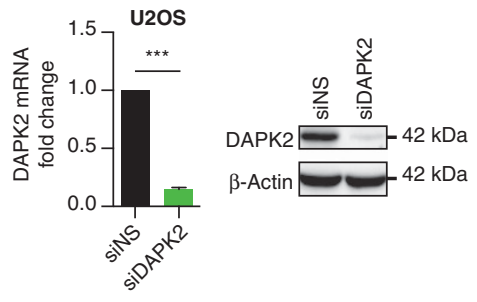

b

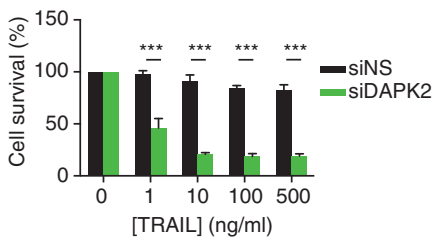

C

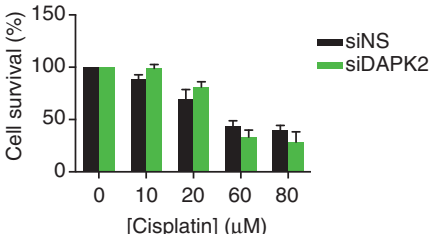

d

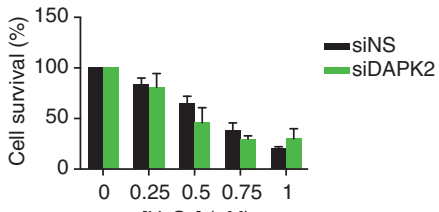

$\left[\mathrm{H}_{2} \mathrm{O}_{2}\right](\mu \mathrm{M})$

e

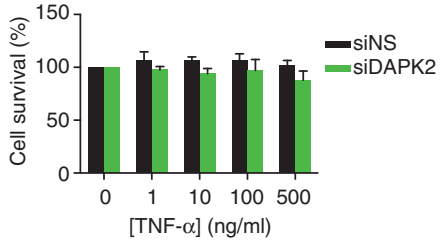

f

\begin{tabular}{llllll} 
siNS & \multicolumn{3}{l}{ siDAPK2 } \\
\hline 0 & 1 & 4 & 0 & 1 & 4
\end{tabular}

Caspase- $8=2=0-55 \mathrm{kDa}$

Cleaved Caspase-8 $=-41 / 43 \mathrm{kDa}$

Cleaved Caspase-8 _ _ $18 \mathrm{kDa}$

$$
\mathrm{BID}--\ldots
$$

Lamin B

(-

$-23 \mathrm{kDa}$

$-68 \mathrm{kDa}$
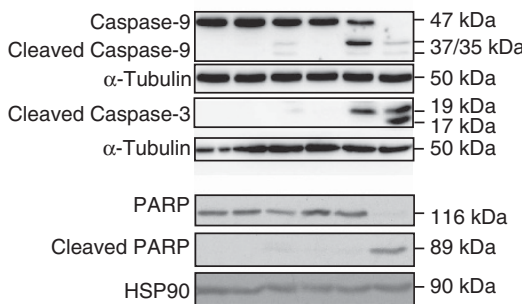

g

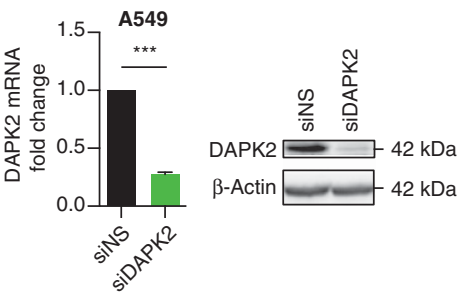

h

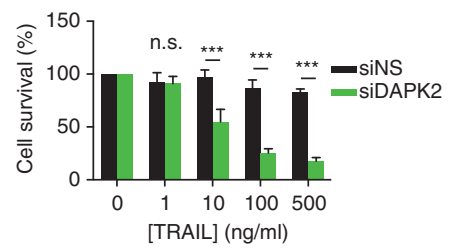

i

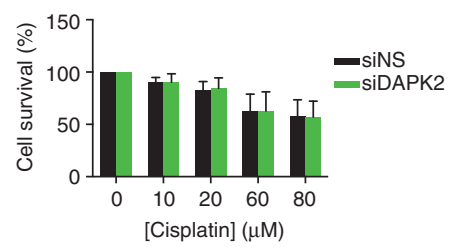

j

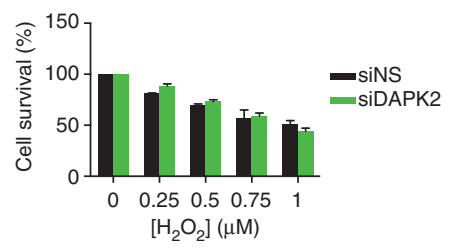

k

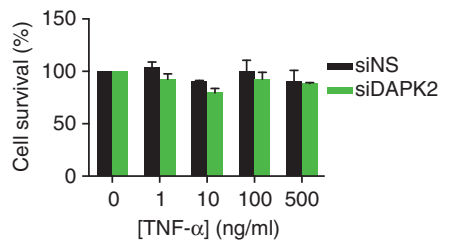

I
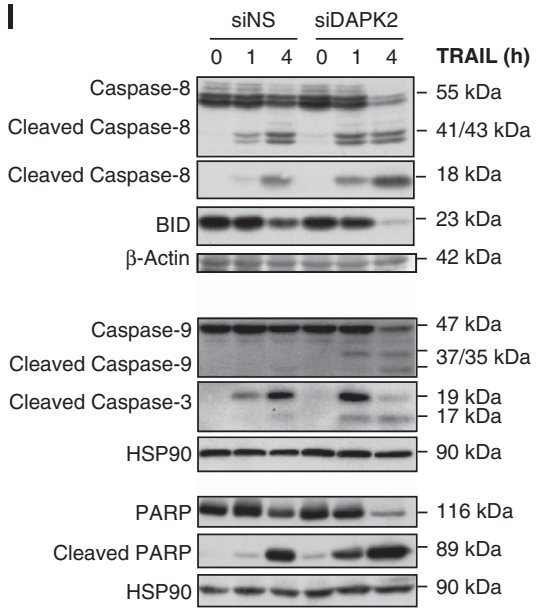

Figure 1 Knockdown of DAPK2 increases apoptotic signalling and sensitises resistant cancer cell lines to TRAIL-induced cell death. U2OS (a-e) and A549 (g-k) cells were transfected with either siNS or DAPK2 siRNA. Forty-eight hours after transfection knockdown efficiency was determined by SDS-PAGE/WB and qPCR (a and $\mathbf{g}$ ). Data represent mean \pm S.E.M. of three independent experiments. Statistical analyses were carried out using Student's $t$-test (paired, one-tailed) $\left.{ }^{* * \star} P<0.005\right)$. For cell survival assays (U2OS in $\mathbf{b}-\mathbf{e}$ and A549 in $\mathbf{h}-\mathbf{k}$ ), cells were replated into 96-well plates at a density of $2 \times 10^{4}$ cells per well $24 \mathrm{~h}$ after siRNA transfection. The following day, cells were treated with the indicated concentrations of TRAIL ( $\mathbf{b}$ and $\mathbf{h}$ ), cisplatin ( $\mathbf{c}$ and $\mathbf{i}), \mathrm{H}_{2} \mathrm{O}_{2}$ ( $\mathbf{d}$ and $\mathbf{j}$ ) and TNF- $\alpha$ (e and $\mathbf{k}$ ) for $24 \mathrm{~h}$. Cells were then fixed using methanol and stained with crystal violet. Crystals were dissolved in $10 \%(\mathrm{v} / \mathrm{v})$ acetic acid and quantified by measuring the absorbance at $595 \mathrm{~nm}$. Values were normalised to the untreated samples. Data represent mean \pm S.E.M. of three independent experiments performed in triplicate. Statistical analyses were carried out using two-way ANOVA test $\left.{ }^{* * *} P<0.005\right)$. Molecular events of TRAIL-induced apoptosis ( $f$ and I) were assessed by SDS-PAGE/WB. Forty-eight hours after A549 and U2OS cells were transfected with siNS and siDAPK2, cells were treated with TRAIL $(100 \mathrm{ng} / \mathrm{ml})$ for the indicated time points. Activation of the extrinsic and intrinsic pathways were assessed by WB using cleavage of BID, caspase-8, caspase-9, caspase-3 and PARP as read-outs. Lamin B, $\alpha$-tubulin and HSP90 served as loading controls 
a
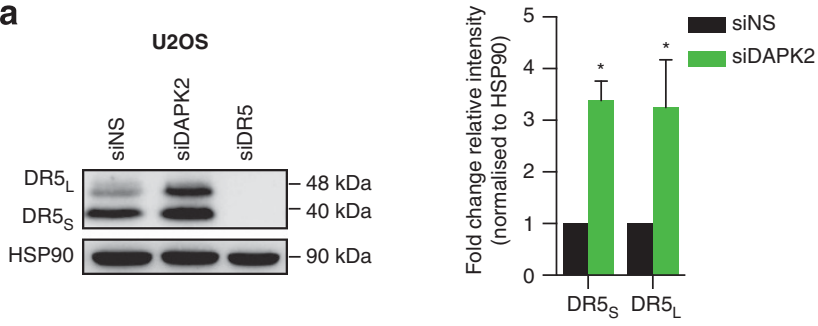

b

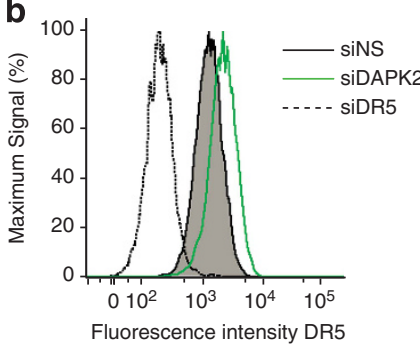

C

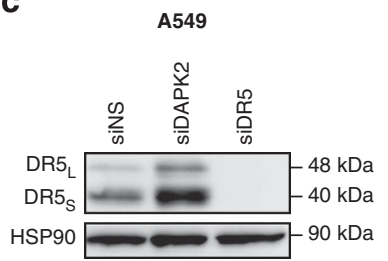

d

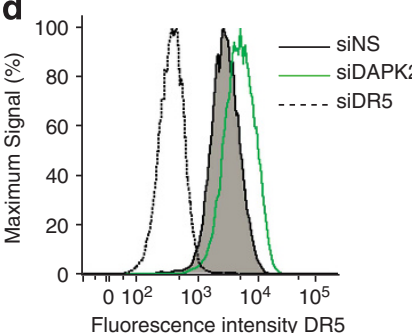

e
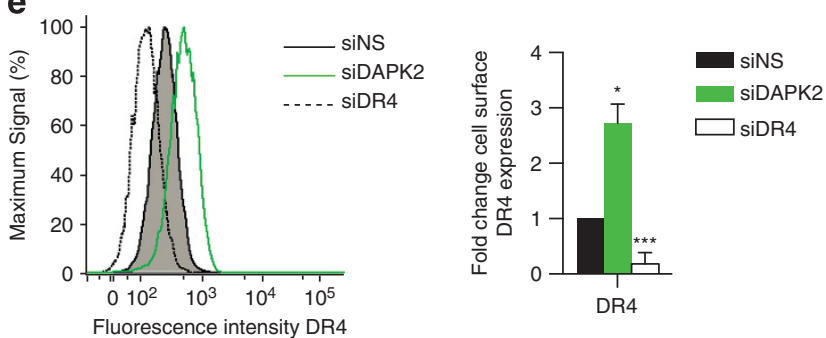

Figure 2 DAPK2 silencing leads to the upregulation of DR5 and DR4, key receptors for TRAIL. U2OS (a and b) and A549 (c-e) cells were transfected with either siNS or siDAPK2 for $48 \mathrm{~h}$. Proteins were isolated and the level of DR expression was assessed by WB (a and $\mathbf{c}$ ) or flow cytometry (b, $\mathbf{d}$ and $\mathbf{e}$ ). Densitometric analyses of WBs were plotted as fold change of DR expression relative to the siNS control. Data represent mean \pm S.E.M. of three independent experiments. Statistical analyses were carried out using one-way ANOVA test $\left({ }^{\star} P<0.05,{ }^{* *} P<0.01\right.$ and $\left.{ }^{* * *} P<0.005\right)$. Cell surface expression quantification was carried out using geometric means of three independent experiments and plotted as fold change of surface expression. Statistical analysis was carried out using Student's $t$-test (paired, one-tailed) $\left({ }^{*} P<0.05\right.$ and $\left.{ }^{* *} P<0.01\right)$ had no impact on the induction or expression of c-FLIP (Supplementary Figure S4), effectively ruling out the induction of FLIP in the upregulation of DR5 and DR4, and, therefore, in the sensitisation process.

In the absence of DR5, DAPK2 can neither sensitise U2OS nor A549 cancer cells to TRAIL-induced apoptosis. The upregulation of DR5 may have been necessary but not sufficient for the sensitisation to TRAIL-induced apoptosis observed after silencing DAPK2 (Figure 1). To determine its relevance, knockdowns targeting concomitantly DAPK2 and DR5 were performed. As controls, cells were transfected with siNS, siDR5 or siBID. BID is part of a well-known amplification loop downstream of TRAIL, which in some cells is required to induce death. Cells were transfected with all permutations of siRNA, as indicated. Downregulation of DR5 per se did not impact on the susceptibility of U2OS or A549 to TRAIL-induced death (Figures $3 a$ and $\mathrm{c}$ ). In contrast, the downregulation of DAPK2-sensitised cells, as shown previously, provided that the expression of DR5 was not downregulated (compare cells transfected with siDAPK2/ siNS versus siDAPK2/siDR5). However, silencing DR5 would almost certainly revert the phenotype observed when DAPK2 was silenced, as this is a key receptor for TRAIL. We, therefore, titrated siDR5 (Figure 3f), measured its impact on DR5 protein expression (Figures $3 f$ and $g$ ) and established the concentration at which only the DAPK2 RNAi effect was reverted $(1.25 \mathrm{nM})$. Co-transfection of U2OS cells with siDAPK2 $(20 \mathrm{nM})$ and siDR5 $(1.25 \mathrm{nM})$ impaired siDAPK2-mediated TRAIL sensitisation (Figure 3h), thus backing up the data shown in Figures $3 a$ and $\mathrm{c}$. This suggested that the upregulation of DR5 following silencing of DAPK2 was critical to sensitise resistant cells to apoptosis. A549 cells also express DR4 and double knockouts of DR4 and DAPK2 suggested that DR4 was partially required to sensitise them to TRAILinduced apoptosis. The effect does not seem to be as pronounced as that seen when DR5 was silenced and, despite the trend shown, it was not statistically significant (Figure 3d). At higher concentrations of TRAIL, DR5 knockdown did not fully revert the phenotype, suggesting that in these cells DR4 might be engaged to overcome impaired DR5 expression (Figures $3 c$ and d). Interestingly, double knockdown of DAPK2 and BID (Supplementary Figure S8) demonstrated that A549 cells required a BID amplification loop for sensitisation (Figure $3 e$ ), whereas U2OS cells did not (Figure $3 b$ ). Overexpression of BCL- $X_{L}$ in U2OS cells further indicated that BID was not involved in the sensitisation to TRAIL achieved in U2OS cells after RNAi against DAPK2 (Supplementary Figure S5).

Increased DR5 expression following DAPK2 knockdown is transcriptionally regulated and not due to altered mRNA or protein stability. Having established that DR5 upregulation was a key event during DAPK2-mediated sensitisation to TRAIL-induced death in A549 and U2OS, we sought to establish within this context how DR5 expression was regulated. Using qPCR, we observed that silencing DAPK2 upregulated the levels of DR5 mRNA in both cell lines (Figures $4 a$ and b). We then conducted classic 

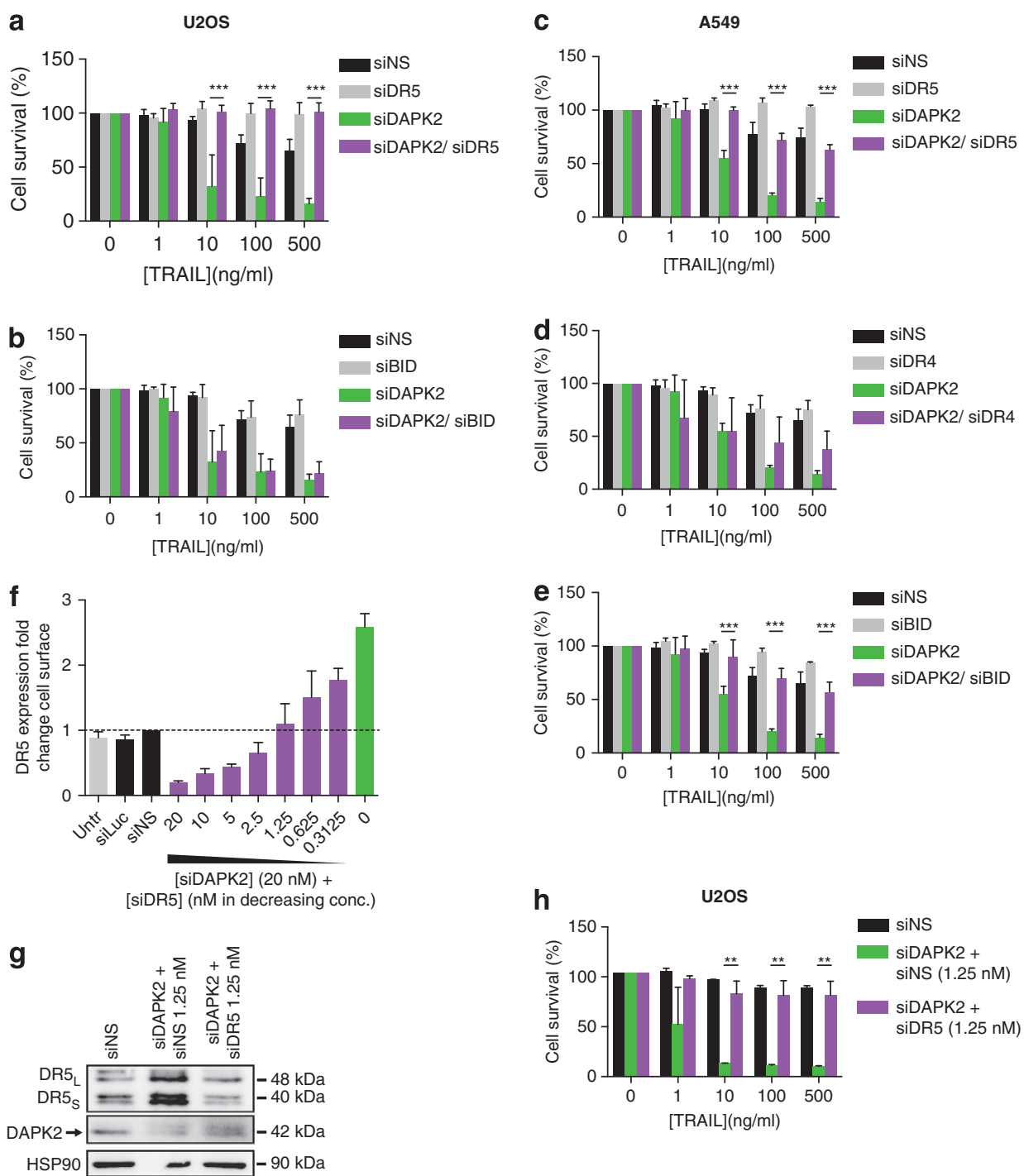

Figure 3 In the absence of DR5, siDAPK2 can neither sensitise U2OS nor A549 to TRAIL-induced apoptosis. Double knockdowns were carried out in U2OS (a and b) and A549 (c-e) cells. For this purpose, cells were transfected with $40 \mathrm{nM}$ of the following siRNA mixtures: (a and c) siNS + siNS, siDR5 + siNS, siDAPK2 + siNS and siDR5 + siDAPK2 and (b and $\mathbf{e}$ ) siNS + siBID and siBID + siDAPK2. A549 cells were also transfected with siNS + siDR4 and siDR4 + siDAPK2 (d). Twenty-four hours after transfection, cells were replated into 96-well plates at a density of $2 \times 10^{4}$ cells per well. The following day cells were treated with TRAIL for $24 \mathrm{~h}$ at the indicated final concentrations. Cells were methanol-fixed and stained with crystal violet. Staining was dissolved in acetic acid and quantified by measuring the absorbance at $595 \mathrm{~nm}$. Values were normalised to the untreated samples. Data represent mean \pm S.E.M. of three independent experiments performed in triplicate. Statistical analysis was carried out using two-way ANOVA test $\left({ }^{*} P<0.05,{ }^{* *} P<0.01\right.$ and $\left.{ }^{* *} P<0.005\right)$. (f) U2OS cells were transfected with either siNS, siLuc (both controls for RNAi off-target effects), siDAPK2 or with siDAPK2 $(20 \mathrm{nM})$ concomitantly with siDR5 $(0.31-20 \mathrm{nM})$ for $48 \mathrm{~h}$. DR5 expression was measured by flow cytometry and cell surface expression quantification carried out as before. Co-transfection of U2OS cells with $1.25 \mathrm{nM}$ siDR5 and $20 \mathrm{nM}$ siDAPK2 abolished siDAPK2-mediated DR5 induction. (g) The effect of co-transfection was also assessed using quantitative WB, which confirmed the results obtained by flow cytometry. (The shadow bands seen in the DAPK2 panel correspond to DR5, as the membrane was probed for with this antibody after being stripped from the anti-DR5 antibody.) (h) To assess the impact of reverting the siDAPK2-mediated effects on DR5 protein levels on cell survival after TRAIL, U2OS cells were transfected with either siDAPK2 $(20 \mathrm{nM})$ and siNS $(1.25 \mathrm{nM})$, or siDAPK2 $(20 \mathrm{nM})$ and siDR5 (1.25 nM). Cells were replated into 96-well plates at a density of $2 \times 10^{4}$ cells per well $24 \mathrm{~h}$ after siRNA transfection and treated the following day with the indicated concentrations of TRAIL for another $24 \mathrm{~h}$. Cell viability was assessed as in (a-e)

experiments with actinomycin D (Figure 4c), which blocks transcription or $\mathrm{CHX}$ (Figure 4f), which blocks translation and thus de novo protein synthesis. Neither DR5 mRNA stability (Figures $4 \mathrm{~d}$ and $\mathrm{e}$ ) nor the protein's half-life (Figures $4 \mathrm{~g}$ and $\mathrm{h}$ ) were significantly altered by reducing the expression levels of DAPK2. The data are therefore consistent with a transcriptional effect.
NF- $\kappa \mathrm{B}$ is phosphorylated and transcriptionally active when DAPK2 is downregulated. DR5 is transcriptionally regulated by the tumour suppressor $\mathrm{p} 53$ and by NF-kB. ${ }^{19}$ Upon silencing DAPK2, there was no change in p53 mRNA levels and both prostate cancer PC 3 cells, which are p53 null, and bladder cancer T24 cells, which have an inactivating mutation in p53, can be sensitised to TRAIL by downregulating 


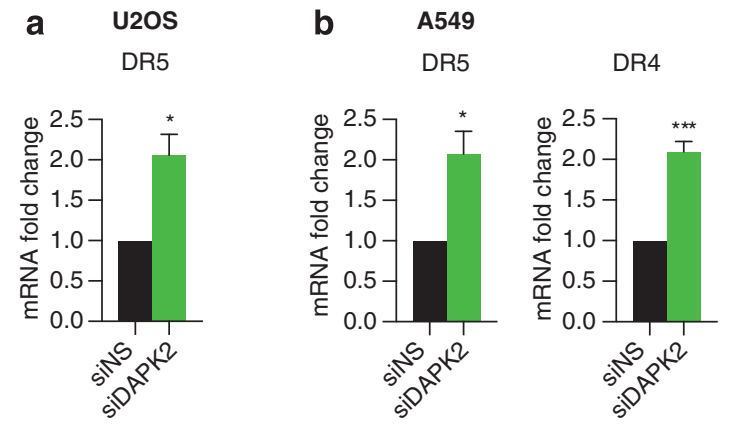

C

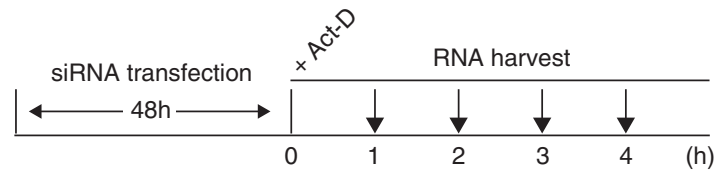

d

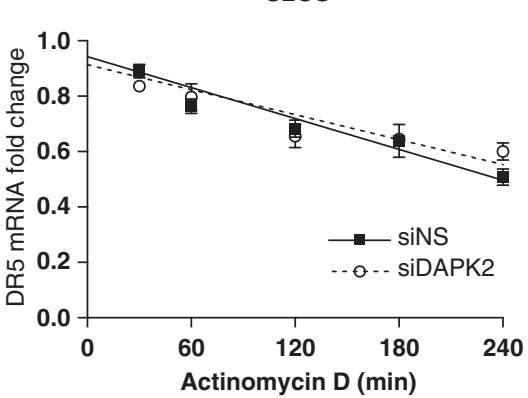

e

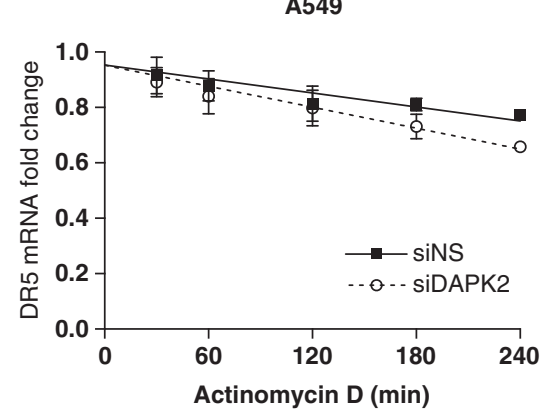

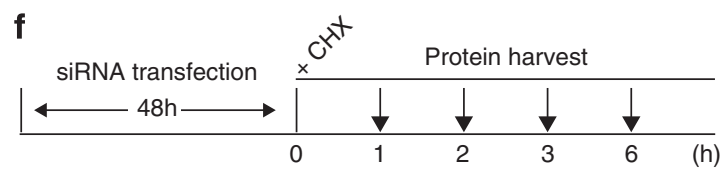

g

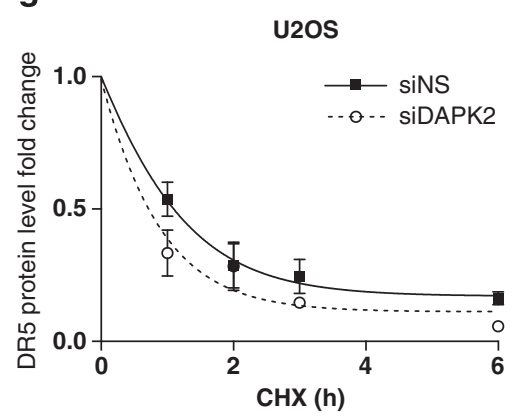

h

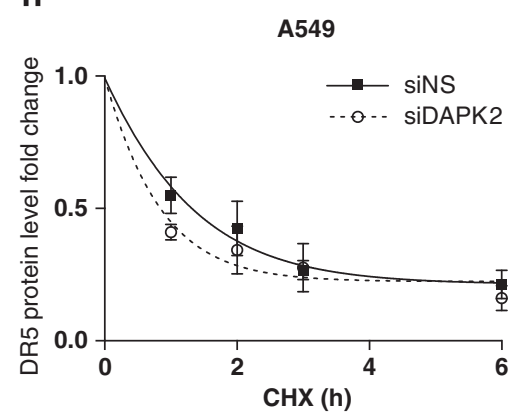

Figure 4 DR5 increased expression following the knockdown of DAPK2 is transcriptionally regulated and not due to alterations on mRNA or protein stability. U2OS (a, d and $\mathbf{g}$ ) and A549 (b, e and $\mathbf{~ h}$ ) cells were transfected with either siNS or siDAPK2. Forty-eight hours after transfection, RNA was harvested and DR5 (U2OS, A549) and DR4 mRNA (A549) levels were analysed by qPCR (a and $\mathbf{b})$. The experimental procedure for analysing DR5 mRNA stability is represented schematically in (c). RNA stability was determined after RNAi against DAPK2 by inhibiting RNA synthesis with actinomycin D (Act-D) over the time periods indicated in the figure (d and e). Experimental procedures used to analyse DR5 protein stability are represented in (f). Protein synthesis was inhibited using cycloheximide (CHX) after $48 \mathrm{~h}$ transfection with siNS and siDAPK2 $(\mathbf{g}$ and $\mathbf{h})$. DR5 protein levels were measured over time using quantitative WB followed by densitometric analysis, where each value was normalised to the corresponding HSP90 loading control. For these analyses, the DR5I isoform was used. The data represent the mean of three independent experiments \pm S.E.M. and no significant changes were detected using a two-way ANOVA test

DAPK2 (Supplementary Figure S6). These data suggested that p53 was not necessary to sensitise TRAIL-resistant cells to TRAIL-induced apoptosis and we thus focused on NF- $\kappa$ B.
Protein expression analysis of NF- $\kappa \mathrm{B}$ components by SDSPAGE/qWB demonstrated that p100 and p52 (NF- $\kappa$ B2) were induced (Figures $5 c$ and d), whereas p105 (NF- $\kappa$ B1) levels 
a

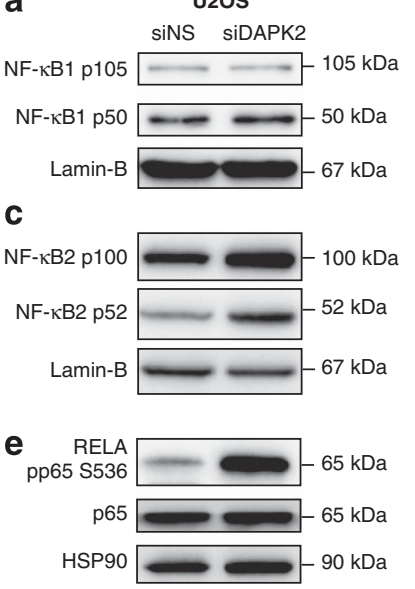

g

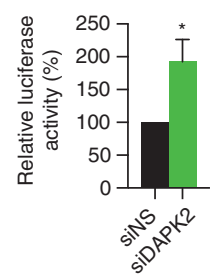

i
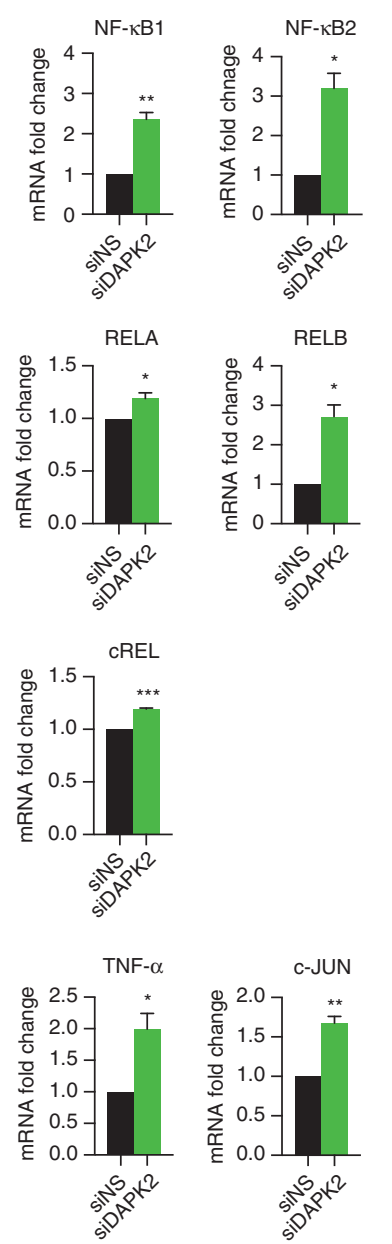

b

A549

siNS siDAPK2
NF-kB1 p105 $-105 \mathrm{kDa}$

NF-kB1 p50 $-50 \mathrm{kDa}$

Lamin-B $67 \mathrm{kDa}$

d

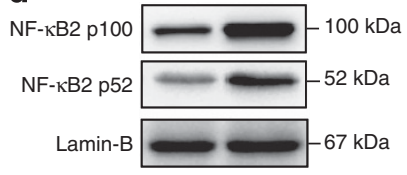

$\mathbf{f}_{\mathrm{pp} 65 \mathrm{SELA}}^{\mathrm{RE}} \longrightarrow-65 \mathrm{kDa}$

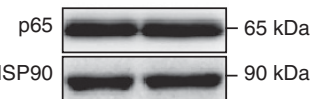

h
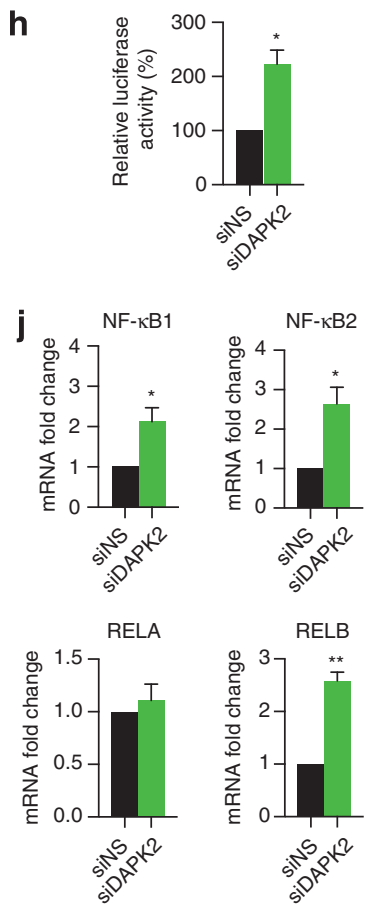

CREL
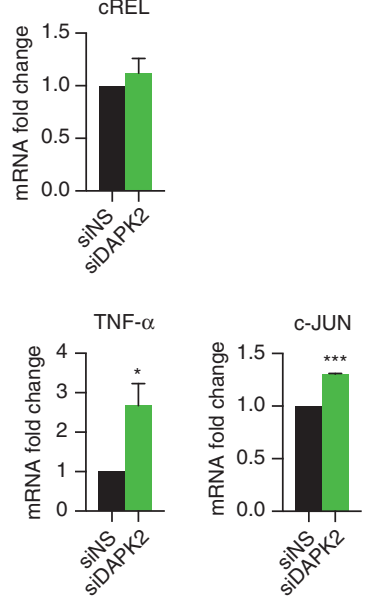

remained unchanged, with a slight increase in its proteolytic cleavage as demonstrated by a 1.5- and 2-fold increase in p50 expression in U2OS and A549 cells, respectively (Figures 5a and b). Importantly, RELA (p65/NF- $\kappa$ B3) was robustly phosphorylated on S536 in both cell lines (Figures $5 e$ and f). This suggested that NF- $\kappa$ B was transcriptionally active when DAPK2 was downregulated, which was confirmed using luciferase reporter assays (Figures $5 \mathrm{~g}$ and $\mathrm{h}$ ). Further analysis of NF- $\kappa \mathrm{B}$ target genes by $\mathrm{qPCR}$, which also included induction of $\mathrm{NF}-\kappa \mathrm{B}$ components, further corroborated that $\mathrm{NF}-\kappa \mathrm{B}$ was activated following RNAi against DAPK2. Indeed, silencing DAPK2 led to robust induction of TNF- $\alpha, c-J U N$, $\mathrm{NF}-\kappa \mathrm{B} 1, \mathrm{NF}-\kappa \mathrm{B} 2$ and RELB, and, although modest, to an increase in RELA and c-REL mRNA levels (Figures $5 i$ and $j$ ). The data are thus consistent with $\mathrm{NF}-\kappa \mathrm{B}$ having a critical role in the aforementioned sensitisation.

NF- $\kappa$ B transcriptionally regulates DR5 expression and leads to sensitisation of osteosarcoma and non-smallcell lung cancer cells to TRAIL-induced apoptosis. The absence of DAPK2 in U2OS and A549 cells sensitised these otherwise resistant cells to TRAIL-induced cell death in what appeared to be an NF- $\kappa \mathrm{B}$-dependent manner. We hypothesised that if NF- $\kappa$ B activation was critical for the sensitisation, then knocking down its components should lead to a reversal of this phenotype. We, therefore, performed RNAi against $\mathrm{NF}-\kappa \mathrm{B} 1, \mathrm{NF}-\kappa \mathrm{B} 2$ or RELA with or without targeting DAPK2 concomitantly (Figure 6 and Supplementary Figure S8) and observed that U2OS cells with silenced DAPK2 became resistant to TRAIL again only when NF- $\kappa$ B1 was absent (Figures $6 \mathrm{a}$ and $\mathrm{c}-\mathrm{e}$ ). In contrast, A549 cells became resistant when either $\mathrm{NF}-\kappa \mathrm{B} 1$ or $\mathrm{NF}-\kappa \mathrm{B} 2$ was silenced (Figures $6 f$ and $\mathrm{h}-\mathrm{j}$ ). Despite its strong phosphorylation, RELA was redundant and its absence per se did not prevent DAPK2 silencing from sensitising U2OS or A549 cells to TRAIL-induced apoptosis. Interestingly, silencing RELB was also without an effect on the sensitisation of U2OS cells to TRAIL-mediated death but it partially blocked sensitisation of A549 cells (Supplementary Figures S7 and S8). Taken together, these data indicate that DAPK2 may be a core, upstream, modulator of TRAIL signalling and that targeting it may affect multiple resistance pathways. We further

Figure $5 \quad N F-k B$ is transcriptionally active upon knockdown of DAPK2. U2OS (a, c, e, $\mathbf{g}$ and i) and $\mathrm{A} 549$ (b, d, f, h and j) cells were transfected with either siNS or DAPK2 siRNA. Forty-eight hours after transfection, the expression levels of NF- $\kappa$ B1 (a and b), NF-KB2 (c and d), RELA pp65-S536 and RELA (e and f) was evaluated by qWB. Lamin-B and HSP90 served as loading controls. Blots shown are representative of three independent experiments yielding identical data. Luciferase assays were performed to assess the transcriptional activity of NF- $\kappa$ B in response to DAPK2 knockdown in U2OS (g) and A549 (h). RNAi-mediated DAPK2 depletion was induced $24 \mathrm{~h}$ before co-transfection with a pNF- $\kappa \mathrm{B}$-Luc reporter Firefly luciferase and a CMV promoter/Renilla-luciferase constructs. Twenty-four hours later, both Firefly- and Renilla-luciferase activities were measured. Data were analysed by normalising the Firefly luciferase to the luminescence obtained for the Renilla-luciferase construct. Data represent mean \pm S.E.M. of three independent experiments performed in triplicate. Statistical analysis was carried out using Student's $t$-test (paired, two-tailed) $\left({ }^{*} P<0.05\right)$. The effect of DAPK2 depletion on the transcription of NF- $\kappa$ B target genes in U2OS (i) and A549 (j) cells was assessed by qPCR after RNAi against DAPK2, which was carried out as described previously. Statistical analysis was carried out using Student's $t$-test (paired, one-tailed) $\left({ }^{\star} P<0.05,{ }^{\star *} P<0.01\right.$ and $\left.{ }^{* \star *} P<0.005\right)$ 
analysed the importance of NF- $\kappa \mathrm{B}$ activation in DR5 transcription using luciferase reporter assays (Figure 6k). The DR5 promoter was engaged upon cell transfection with siDAPK2 (Figures $6 \mathrm{l}$ and $\mathrm{n}$ ), and this engagement was abrogated if the NF- $\kappa \mathrm{B}$ binding site on this promoter was abolished (Figures $6 \mathrm{k}, \mathrm{m}$ and $\mathrm{o}$ ), indicating an absolute requirement for $\mathrm{NF}-\kappa \mathrm{B}$ in siDAPK2-mediated DR5 upregulation.

\section{Discussion}

As DAPK2 shares $\sim 80 \%$ of homology to DAPK1 in the kinase domain but has no discernible death domain ${ }^{12}$ (Supplementary Figure S1), we hypothesised that depending on the cellular content and expression levels of DAPK2 this kinase would work either as a pro- or antiapoptotic protein. Here, we have shown that RNAi-mediated depletion of DAPK2 (Figures 1a and g) specifically sensitises U2OS and A549 cells to TRAIL-induced apoptosis (Figures $1 \mathrm{~b}$ and $\mathrm{h}$ ), but not to a wide range of other apoptotic stimuli (Figures $1 \mathrm{c}-\mathrm{e}$ and $\mathrm{i}-\mathrm{k}$ ).

Downregulation of DAPK2 leads to TRAIL-mediated activation of both extrinsic and intrinsic death pathways (Figure 7), and this is quicker in A549 cells than in U2OS cells (Figures $1 \mathrm{f}$ and I). Interestingly, activation of the intrinsic signalling appears dispensable in U2OS cells (Figure 3b and Supplementary Figure S5) but represents a crucial part of TRAIL-induced apoptosis upon DAPK2 depletion in A549 cells (Figure 3e). Many mechanisms of TRAIL resistance and strategies to overcome these involve the DISC complex, including downregulation of c-FLIP. ${ }^{20}$ Inhibition of BCL-2/ $B C L-X_{L}$ has also been shown to resensitise cells to TRAILinduced apoptosis. ${ }^{21,22}$ There was no change on FLIP upon siDAPK2 (Supplementary Figure S4) and overexpressing $B C L-X_{L}$ had no impact on DAPK2-mediated sensitisation of U2OS to TRAIL (Supplementary Figure S5), suggesting that these molecules are factors of TRAIL resistance that are unlikely to be surpassed by silencing DAPK2. Perhaps, the most prominent mechanism to overcome TRAIL resistance is the upregulation of its receptors, DR4 and/or DR5. DAPK2 depletion leads to a significant increase of DR5 protein in U2OS and A549 cells (Figures 2a-d). In A549 cells, it also increases the expression of DR4 (Figure 2e). Such receptor upregulation is essential for the sensitisation of U2OS and A549 cells to TRAIL-induced apoptosis following downregulation of DAPK2 (Figure 3).

DR expression can be induced by several chemicals, which can cause either their mRNA stabilisation ${ }^{23}$ or transcriptional upregulation by various transcription factors. ${ }^{19,24}$ DR induction leads to an increase in the number of receptor molecules on the cell surface, thus overcoming the threshold required to sensitise cells to TRAIL cytotoxicity. As U2OS cells do not express DR4 and silencing DAPK2 leads to the upregulation of DR5 in both U2OS and A549 cells (Figure 2), we focused on the regulation of DR5 induction/expression upon DAPK2 depletion. We showed that depletion of DAPK2 does not increase the mRNA (Figures $4 c-e$ ) or protein (Figures $4 \mathrm{f}-\mathrm{h}$ ) stability of DR5. However, DR5 and DR4 mRNAs are elevated after silencing DAPK2 (Figures $4 a$ and $b$ ), suggesting that inhibition of DAPK2 leads to the transcriptional regulation of DRs.
DR5 is regulated by a variety of transcription factors such as p53 and NF-kB. ${ }^{19}$ The fact that DAPK2 silencing can also sensitise p53-mutated (mt) T24 colon cancer cells and p53-null prostate cancer PC3 cells rules out the absolute requirement for p53 (Supplementary Figure S6). In contrast, activation of $\mathrm{NF}-\kappa \mathrm{B}$ (Figure 5 ) is absolutely essential (Figure 6 and Supplementary Figures S7 and S8). This is interesting as $\mathrm{NF}-\kappa \mathrm{B}$ has an ambiguous role in TRAIL signalling. For example, there are reports suggesting an antiapoptotic role for $\mathrm{NF}-\kappa \mathrm{B}$, involving the upregulation of $\mathrm{DcR} 1^{25}$ or of antiapoptotic BCL- $\mathrm{X}_{\mathrm{L}}{ }^{26}$ whereas other reports suggest a proapoptotic role due to the induction of DR4 or DR5. ${ }^{19,24}$ Interestingly, binding of TRAIL to DcR2 has been shown to activate NF- $\kappa \mathrm{B}$, which then initiates a negative feedback loop protecting cells from TRAIL-induced apoptosis. ${ }^{27}$ Using an $\mathrm{NF}-\kappa \mathrm{B}$ reporter plasmid, we were able to show that $\mathrm{NF}-\kappa \mathrm{B}$ is transcriptionally active in both U2OS and A549 cells following DAPK2 knockdown (Figures $5 g$ and $h$ ). RELA is phosphorylated on S536 (Figures 5e and f), and NF- $\kappa \mathrm{B} 1$ and NF- $\kappa \mathrm{B} 2$ are upregulated (Figures $5 \mathrm{a}-\mathrm{d}$ ) in response to DAPK2 knockdown. NF- $\kappa \mathrm{B}$ signalling is highly complex and different members assemble in different dimmers, which then participate in canonical and non-canonical signalling pathways. Canonical pathways tend to involve NF- $\kappa$ B1 and RELA, whereas the non-canonical pathway is thought to involve primarily NF- $\kappa \mathrm{B} 2$ and RELB. This distinction is not absolute and a great deal of signalling specificity is determined by the cell type and cellular environment. ${ }^{28}$ Indeed, NF- $\kappa \mathrm{B} 1, \mathrm{NF}-\kappa \mathrm{B} 2$ and RELB were robustly induced in response to RNAi against DAPK2 both in U2OS and A549 cells, and there was a hint of an induction of RELA and c-REL (Figures $5 i$ and $j$ ). To unravel the complex role of NF- $\mathrm{KB}$ in TRAIL signalling, we performed double-knockdown experiments (Figure 6). By analysing the effect of TRAIL on U2OS and A549 cells transfected with siDAPK2 concomitantly with siRNAs directed against NF- $\kappa \mathrm{B}$ family members, we identified NF- $\kappa \mathrm{B} 1$ as key molecules responsible for sensitisation to TRAIL-induced apoptosis in response to DAPK2 depletion. Interestingly, in A549 cells, knockdown of NF- $\kappa$ B2 and RELB in combination with DAPK2 also resulted in a partial rescue (Figure $6 i$ and Supplementary Figure S7b). It thus appears that U2OS cells require mainly the activation of the $\mathrm{NF}-\kappa \mathrm{B}$ canonical pathway, whereas A549 cells require activation of both the canonical and non-canonical pathways. It is still unclear why this is but it is fair to assume that, due to distinct cellular environments in these two cell lines, silencing DAPK2 leads to the formation of different NF- $\kappa \mathrm{B}$ dimers, which are nevertheless capable of resulting in an identical biologic response, namely upregulation of DR5. The fact that A549 seem to also require BID to be fully sensitised to TRAIL after DAPK2 silencing may be related to the partial requirement for $\mathrm{NF}-\kappa \mathrm{B} 2 / \mathrm{RELB}$. It is also possible that $\mathrm{NF}-\kappa \mathrm{B} 2$ and/or RELB are required to induce DR4, which is not expressed in U2OS cells. Using DR5 promoter luciferase constructs with either wild-type (wt) or NF- $\kappa \mathrm{B}-\mathrm{mt}$ consensus sites, we established the necessity of NF- $\kappa \mathrm{B}$ as a transcription factor required for the induction of DR5 in response to DAPK2 depletion. Recently, Yoo et al. ${ }^{29}$ suggested that DAPK1 could function as a repressor for NF $-\kappa \mathrm{B}$ activation. ${ }^{29}$ Additionally, NF- $\kappa \mathrm{B}$ activation 
downstream of T-cell receptor signalling is increased in DAPK1-knockout cells. ${ }^{30}$ As all DAPKs are thought to form multiprotein complexes, ${ }^{31}$ the activation of NF- $\kappa \mathrm{B}$ proteins upon DAPK2 knockdown is likely to be caused by at least some of the same molecular events described for DAPK1. Different NF- $\kappa$ B family members can thus differentially regulate TRAIL receptors, which is reflected by sensitisation to TRAIL following DAPK2 silencing being dependent on NF- $\kappa$ B1 in U2OS and A549 cells and by the additional requirement of $\mathrm{NF}-\kappa \mathrm{B} 2$ and $\mathrm{RELB}$ in A549 cells.

The question thus remains how downregulating DAPK2 leads to the activation of NF- $\kappa \mathrm{B}$ (Figure 5), vital to sensitising resistant cells to TRAIL-mediated death (Figure 6). The

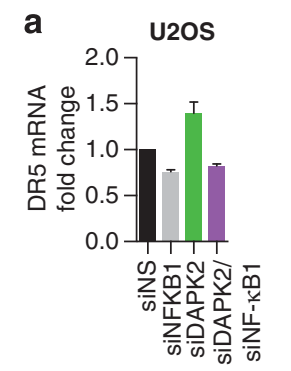

b
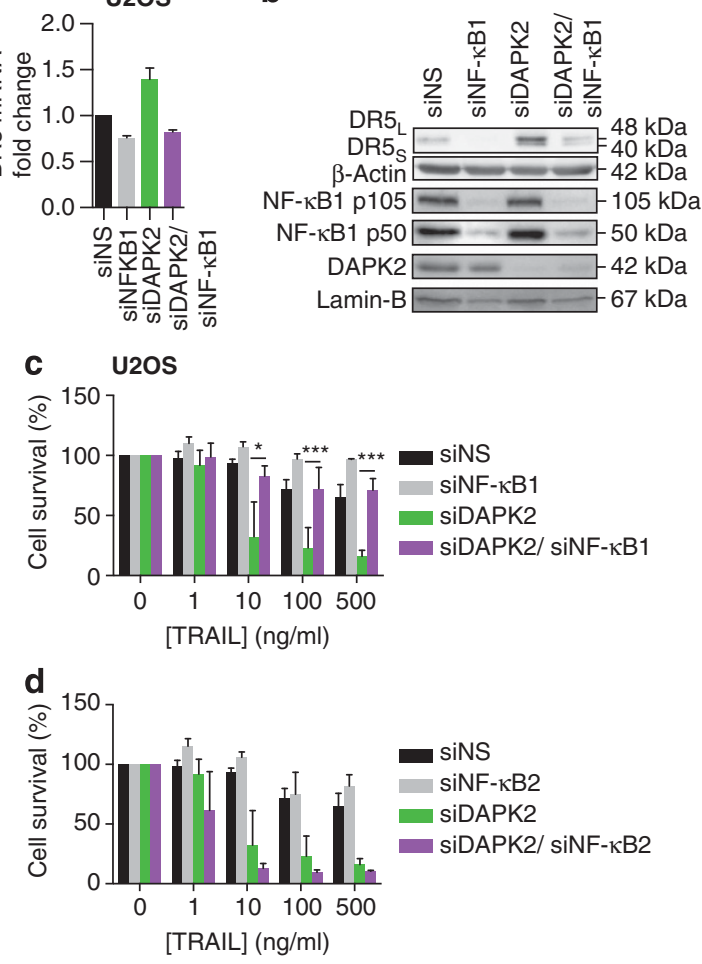

e

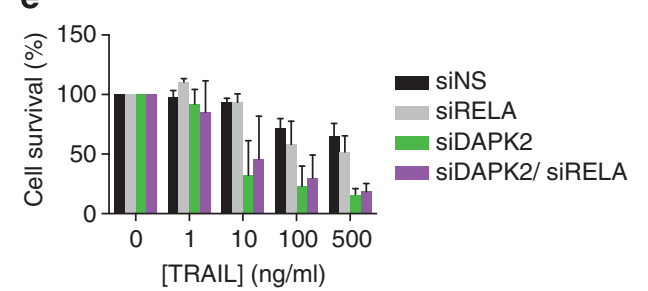

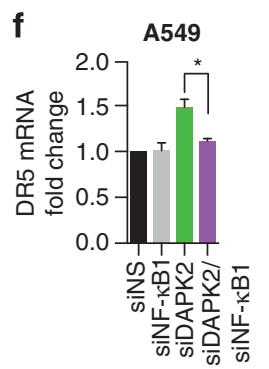

g
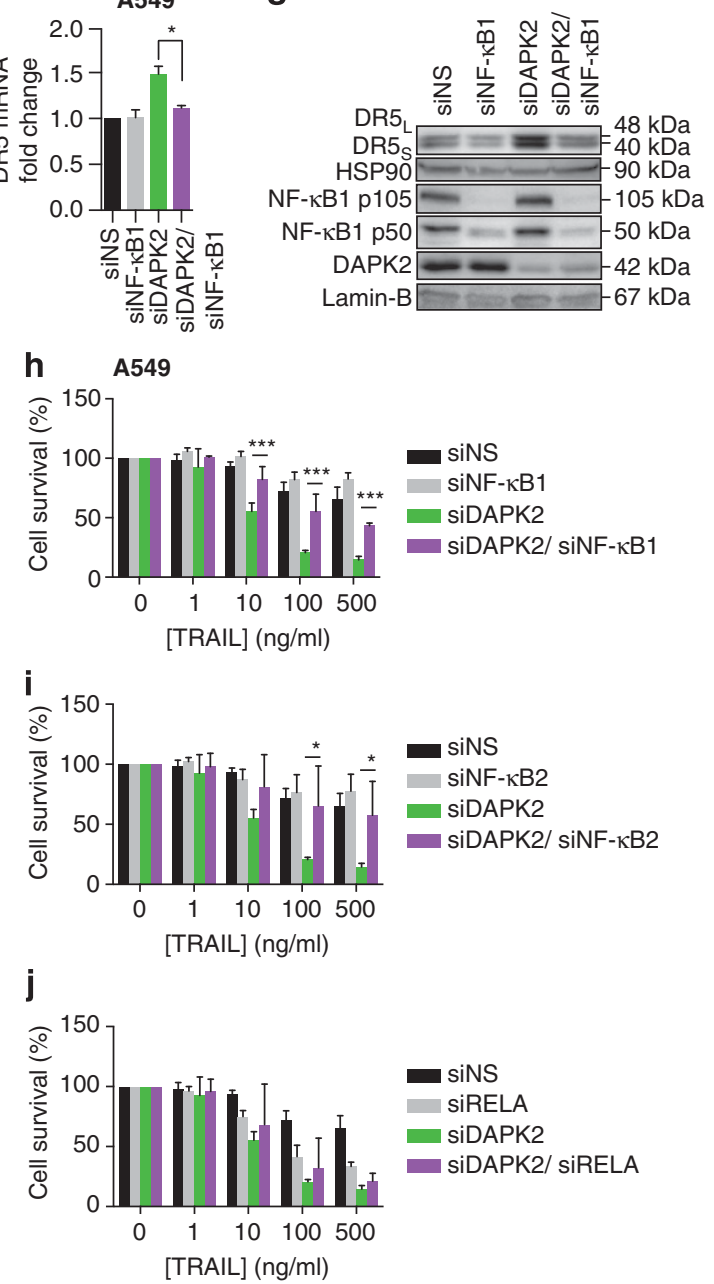

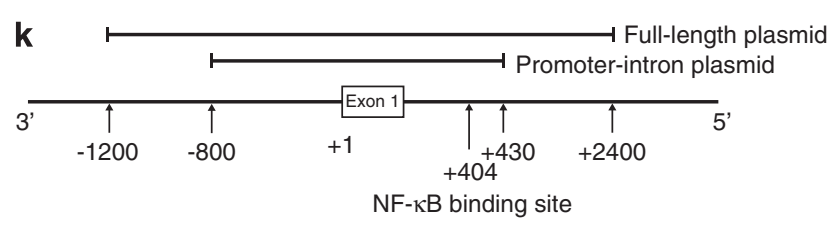

DR5 genomic locus
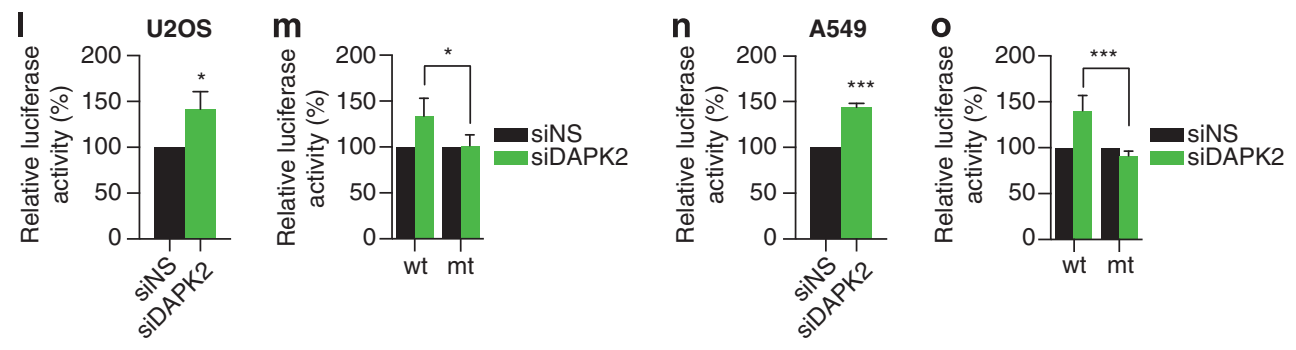
involvement of $\mathrm{NF}-\kappa \mathrm{B}$ in TRAIL signalling is highly cell context-dependent and DAPK2 likely regulates an upstream component of NF- $\kappa \mathrm{B}$ signalling. Such a component may be the NF- $\kappa \mathrm{B}$-negative regulator, $\mathrm{I}_{\kappa} \mathrm{B}$. Indeed, silencing DAPK2 leads to its disappearance (not shown), which is probably the main cause for the activation of $\mathrm{NF}-\kappa \mathrm{B}$. This then poses the question of why $\mathrm{I} \kappa \mathrm{B}$ is being degraded and the most immediate hypothesis is that it is being phosphorylated by IKKs, coupled to the TRAIL receptor complex. Such coupling may occur via RIP and/or TRADD. ${ }^{32}$ Perhaps, DAPK2

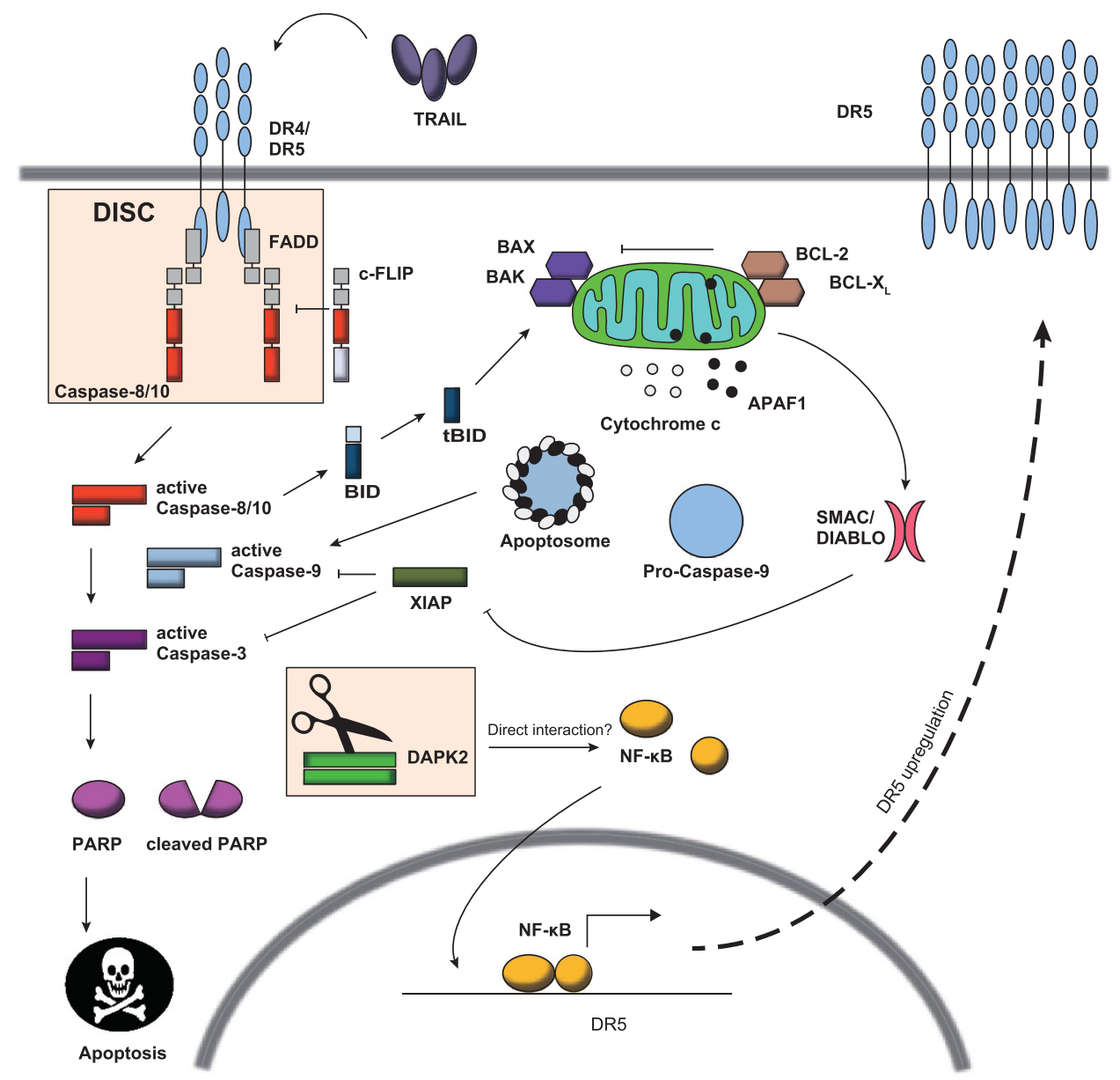

Figure 7 DAPK2 is a novel modulator of TRAIL-induced apoptosis. Death receptor ligation by TRAIL primarily activates the extrinsic apoptotic pathway. TRAIL binding induces DISC formation. Activation of the initiator caspases-8/10 leads to proteolytic cleavage and activation of downstream effector caspases such as caspase-3, which eventually culminates in apoptosis. TRAIL can also activate the intrinsic apoptotic pathway via BID. This involves depolarisation of the mitochondrial membrane potential via BAK and BAX, followed by cytochrome $c$ release and downstream activation of caspase-9. Resistance mechanisms can occur at many different stages of the cascade. c-FLIP can inhibit the activation of initiator caspases within the extrinsic pathway, XIAP can block the action of effector caspases and antiapoptotic members of the BCL-2 family, such as BCL-X and BCL-2, which are known inhibitors of the intrinsic apoptosis pathway. Depletion of DAPK2 triggers the activation of NF- $\kappa$ B and leads to NF- $\kappa$ B-mediated induction of DR5 mRNA and to an increase in DR5 protein levels. The increase in the number of DR5 molecules presumably overcomes the inhibition threshold and lead to the resensitisation of cancer cells to TRAlL-induced apoptosis

Figure 6 The transcription factor NF- $\kappa \mathrm{B}$ is a critical component of DR5 expression and is necessary for the sensitisation to TRAIL-induced cell death seen after DAPK2 silencing. U2OS (a-e, I and $\mathbf{m}$ ) and A549 ( $\mathbf{f}-\mathbf{j}, \mathbf{n}$ and $\mathbf{o})$ cells were transfected with either siNS or the following siRNA 1:1 mixes: siNF- $\kappa$ B1 + siNS, siDAPK2 + siNS and siDAPK2 + NF- $\kappa$ B1 ( $40 \mathrm{nM}$ in total). Forty-eight hours after transfection, RNA and proteins were isolated and levels of DR5 mRNA (a and $\mathbf{f})$ and protein were measured $(\mathbf{b}$ and $\mathbf{g})$. For mRNA, data represent mean \pm S.E.M. of two independent experiments in U2OS cells (a) and three independent experiments in A549 (f). Statistical analyses were carried out using Student's $t$-test (paired, two-tailed) ( $\left.{ }^{*} P<0.05\right)$. For protein, DR5 levels and knockdown verification were achieved with qWB, using lamin $B$ as a loading control. Cell survival analyses in response to TRAIL after the double knockdowns were carried out in U2OS and A549 cells that were transfected with either siNS or the following siRNA 1:1 mixes: siNF- $\kappa$ B1 + siNS, siDAPK2 + siNS, siDAPK2 + NF- $\kappa$ B1 (c and $\mathbf{h})$, siNS + siNF- $\kappa$ B2, siDAPK2 + siNF- $\kappa$ B2 (d and i) and siNS + siRELA, siDAPK2 + siRELA (e and j). Twenty-four hours after transfection, cells were replated into 96-well plates at a density of $2 \times 10^{4}$ cells per well and treated with TRAIL for $24 \mathrm{~h}$ at the indicated final concentrations the day after. Crystal violet viability assays were carried out as described previously. Values were normalised to the untreated samples. Data represent mean \pm S.E.M. of three independent experiments performed in triplicate. Statistical analysis was carried out using two-way ANOVA test $\left({ }^{\star} P<0.05,{ }^{* *} P<0.01\right.$ and $\left.{ }^{* \star *} P<0.005\right)$. Plasmids used for DR5 promoter analyses are represented in $(\mathbf{k})$. As before, DAPK2 depletion was initiated $24 \mathrm{~h}$ before co-transfection with the DR5 full-length promoter (I and $\mathbf{n})$, DR5 promoter-intron wt or NF- $\kappa$ B-mt ( $\mathbf{m}$ and $\mathbf{o}$ ) plasmid Firefly-luciferase pGL3 construct and a CMV promoter/Renilla-luciferase construct. Twenty-four hours later, both Firefly- and Renilla-luciferase activities were measured. Data were analysed by normalising the Firefly luciferase to the luminescence obtained for the Renilla-luciferase activity. Data represent mean \pm S.E.M. of three independent experiments. Statistical analysis was carried out using Student's $t$-test (paired, two-tailed) $\left({ }^{*} P<0.05\right.$ and $\left.{ }^{* * *} P<0.005\right)$ 
interacts with the TRAIL receptor complex and it acts as a 'plug' that stops cells from 'inadvertently' succumbing to TRAIL. Removing DAPK2 may free binding sites necessary to couple the pathway to the initiator caspases and to NF- $\kappa \mathrm{B}$. It is also possible that the interaction between $\mathrm{NF}-\kappa \mathrm{B}$ signalling components and DAPK2 occurs in the cytoplasm rather than at the membrane with IKKs and IKB being the most likely interactors. DAPK2 may alternatively repress $\mathrm{NF}-\kappa \mathrm{B}$ by, for example, protecting the cell from cellular stress, known to activate NF- $\kappa \mathrm{B}$. Whichever way DAPK2 silencing leads to NF- $\kappa \mathrm{B}$ activation, NF- $\kappa \mathrm{B}$ activation per se, in response to a classic NF- $\kappa$ B activator such as TNF- $\alpha$, leads to the degradation of DAPK2 (not shown). What is intriguing is why the output of the TRAIL stimulus is death, as $\mathrm{NF}-\kappa \mathrm{B}$ also leads to the activation of key survival genes. The balance must thus rest on the faster caspase activation observed following DAPK2 silencing and on the NF- $\kappa \mathrm{B}$ mediated induction of DR5 and/or DR4. Clearly, our understanding of how DAPK2 and NF- $\kappa$ B interact is in its infancy and much remains to be understood.

Overall, our work suggests that inhibition of DAPK2 in combination with TRAIL or TRAIL mimics may provide an alternative, novel, approach to overcome TRAIL resistance via activating proapoptotic functions of the NF- $\kappa$ B response, and may ultimately open new avenues for treatments of certain types of malignancies.

\section{Materials and Methods \\ Cell culture. U2OS and A549 cells were grown in Dulbecco's modified Eagle's medium supplemented with $10 \%$ (v/v) foetal calf serum (FirstLink, Wolverhampton, UK), $2 \mathrm{mM}$ L-glutamine, $50 \mathrm{U} / \mathrm{ml}$ penicillin and $50 \mu \mathrm{g} / \mathrm{ml}$ streptomycin (Sigma- Aldrich, St. Louis, MO, USA) in a humidified atmosphere of $10 \% \mathrm{CO}_{2}$ at $37^{\circ} \mathrm{C}$. TRAIL and TNF- $\alpha$ were from PeproTech (London, UK) and all other chemicals were from Sigma-Aldrich.}

Antibodies. Anti-DAPK2 was purchased from Epitomics (Burlingame, CA, USA). Antibodies against DR5, NF- $\kappa$ B1 (p50, p105), NF- $\kappa$ B2 (p52, p100), RELA (p65), phosphorylated RELA (pp65-S536), BID, PARP, BCL-X, caspase-3, caspase-8 and caspase-9 were bought from Cell Signaling Technology (Cambridge, UK). The antibodies against $\beta$-actin, $\alpha$-tubulin and Flag were obtained from Sigma-Aldrich and the one against HSP90 was from NeoMarkers (Fremont, CA, USA). The antibody against lamin B was from Santa Cruz Biotechnology (Santa Cruz, CA, USA). Secondary antibodies were from Dako (Glostrup, Denmark). For flow cytometry, the antibody against DR5 was from eBioscience (Hatfield, UK) and the one against DR4 was from Abcam (Cambridge, UK).

RNAi. RNAi was performed as described before ${ }^{16}$ using Lipofectamine RNAiMax (Invitrogen, Paisley, UK). Briefly, cells plated at $2.5 \times 10^{5}$ in 6 -well plates were left untransfected or were transfected with either $20 \mathrm{nM}$ AllStars negative control siRNA (Qiagen, Hilden, Germany) or $20 \mathrm{nM}$ siGENOME pooled siRNA (Dharmacon, Lafayette, CO, USA) to DAPK2 (oligonucleotides 3 and 4), DR4, DR5, BID, NF- $\kappa$ B1, NF- $\kappa$ B2 and RELA (pool of four oligonucleotides) (Supplementary Table SI). A custom-made siDAPK-3'-UTR oligonucleotide from Dharmacon and another $3^{\prime}$-UTR-targeting siDAPK2 oligonucleotide from Qiagen (Hs_DAPK2_11 FlexiTube siRNA) were also used. For double knockdowns, equal amounts of AllStars negative control and/or targeting siRNA were mixed to a final concentration of $40 \mathrm{nM}$. To avoid variability in cell numbers, $24 \mathrm{~h}$ after transfection, cells were counted and replated at identical numbers. Cells were then treated and analysed as described in the figures using the methods described below.

Cell survival assays. Cells were plated in triplicate in 96-well plates $\left(2 \times 10^{4}\right.$ cells per well) and treated the next day with different concentrations of TRAIL, cisplatin, $\mathrm{H}_{2} \mathrm{O}_{2}$ or TNF- $\alpha$ for $24 \mathrm{~h}$, as indicated in the figures. Cell survival was assessed using crystal violet staining. For that purpose, cells were washed in phosphate-buffered saline (PBS), and fixed and stained with $0.5 \%$ (w/v) crystal violet in $25 \%(\mathrm{v} / \mathrm{v})$ methanol for $30 \mathrm{~min}$. The plates were then thoroughly washed with water, dried and the dried dye dissolved in $10 \%$ (v/v) acetic acid. The absorbance was measured at $595 \mathrm{~nm}$ in a spectrophotometer. Apoptosis was also determined by studying cell cycle profiles: cells were washed two times with PBS and fixed with ice-cold $70 \%(\mathrm{v} / \mathrm{v})$ ethanol for $30 \mathrm{~min}$. After two additional washing steps, cells were incubated with $20 \mu \mathrm{g} / \mathrm{ml}$ ribonuclease A (Qiagen) and stained with $50 \mu \mathrm{g} / \mathrm{ml} \mathrm{PI}$ for $15 \mathrm{~min}$ in the dark. Cells were processed using a flow cytometer and the data were analysed using FlowJo version 8.8.7 (Tree Star Inc., Ashland, OR, USA).

Western blotting. Proteins were extracted using radioimmunoprecipitation assay buffer (RIPA; $50 \mathrm{mM}$ Tris- $\mathrm{HCl}(\mathrm{pH} 7.4), 0.5 \%$ (v/v) NP-40, $150 \mathrm{mM} \mathrm{NaCl}$, $1 \mathrm{mM}$ EDTA, $1 \mathrm{mM} \mathrm{Na}_{3} \mathrm{VO}_{4}$ and 'cOmplete and Mini, EDTA-free protease inhibitor cocktail', the latter used as instructed by the manufacturer; Roche, Mannheim, Germany). Concentrations were determined using a Bradford assay according to the manufacturer's instructions. They were then analysed by SDS-PAGE/qWB. Membranes were blocked and secondary antibodies diluted in $5 \%(\mathrm{w} / \mathrm{v})$ non-fat milk/TBS-Tween-20 and primary antibodies were dissolved in $5 \%(\mathrm{w} / \mathrm{v})$ BSA/TBS-Tween-20. WBs were analysed using the quantitative luminescence system Fusion SOLO (Analis, Ghent, Belgium). Densitometric analysis was performed using Image Studio Lite software (LI-COR Biosciences, Lincoln, NE, USA) (http: //www.licor.com/islite).

Flow cytometry. Cells were incubated with anti-DR4-FITC or anti-DR5-PE for $1 \mathrm{~h}$ at $4^{\circ} \mathrm{C}$, washed five times with cold PBS and fixed with $1 \%(\mathrm{w} / \mathrm{v})$ p-formaldehyde. Cells were analysed using a FACS Canto (Becton Dickinson, Franklin Lakes, NJ, USA) and data were analysed with FlowJo Version 8.8.7. Geometric means were used for the analyses. ${ }^{16}$

Real-time PCR. Gene expression analysis was carried out by quantitative two-step reverse transcription PCR. Reverse transcription was performed using total RNA and the High Capacity cDNA Reverse Transcription kit (Life Technologies, Carlsbad, CA, USA), using random hexamers. qPCR was carried out using the Fast SYBR Green Master Mix (Applied Biosystems, Foster City, CA, USA) with specific primer pairs (Supplementary Table SII). For each target mRNA analysed, $2.5 \mu \mathrm{l}$ of Fast SYBR Green Master Mix, $0.5 \mu \mathrm{M}$ of each primer pair and $2 \mu \mathrm{l}$ of cDNA in deionised water $(5 \mathrm{ng} / \mu \mathrm{l})$ were mixed in 384-well plates in duplicates using Matrix Equalizer Electronic Multichannel Pipetters (Thermo Fisher Scientific, Waltham, MA, USA). qPCR was carried out on an ABI PRISM 7900HT (Applied Biosystems) using the following settings: initial activation of $20 \mathrm{~s}$ at $95^{\circ} \mathrm{C}, 40$ cycles; denaturation for $1 \mathrm{~min}$ at $95^{\circ} \mathrm{C}$; annealing/extension for $20 \mathrm{~s}$ at $60^{\circ} \mathrm{C}$; final melting curve was carried out for $15 \mathrm{~s}$ at $95^{\circ} \mathrm{C}$ and then $15 \mathrm{~s}$ at $60^{\circ} \mathrm{C}$. Quantification of target messages was performed using qbasePLUS software (Biogazelle, Ghent, Belgium). HPRT and GAPDH were the reference genes used for normalisation.

Co-transfection of adherent cells with siRNA and DNA. Cotransfection was performed using Attractene transfection reagent (Qiagen). Briefly, cells plated at density of $4 \times 10^{5}$ in 6 -well plates were transfected with either $40 \mathrm{nM}$ Allstars negative control siRNA or $40 \mathrm{nM}$ siDAPK2 and $1.2 \mu \mathrm{g}$ DNA of empty vector control, or PCDNA3.BCL- $X_{L}$ plasmid, which was kindly provided by Dr. Ingram laccarino (Institute of Human Genetics, University Hospital SchleswigHolstein, Kiel, Germany). Protein expression was analysed by qWB and cell death using crystal violet assays.

Plasmids. The DR5 full-length promoter pGL3 construct and DR5 promoterintron wt and NF- $\kappa \mathrm{B}-\mathrm{mt} \mathrm{pGL} 3$ constructs were kindly provided by Professor Spencer Gibson (University of Manitoba, Winnipeg, MB, Canada). pNF- $\kappa$ B-Luc reporter vector was from Clontech (Saint-Germain-en-Laye, France). The BCL-X expression plasmid was a gift from Dr. Ingram laccarino (Institute of Human Genetics, University Hospital Schleswig-Holstein, Kiel, Germany).

Luciferase assays. Cells were transfected with siRNA oligonucleotides as described above. Twenty-four hours later, cells were co-transfected with $100 \mathrm{ng}$ of pNF- $\kappa$ B-Luc, DR5 full-length promoter Firefly-luciferase pGL3, DR5 promoter-intron wt Firefly-luciferase pGL3 or DR5 promoter-intron NF- $\kappa$ B-mt Firefly-luciferase pGL3 constructs and $10 \mathrm{ng}$ of CMV promoter Renilla-luciferase 
$\mathrm{pRL}$ construct using Attractene transfection reagent (Qiagen). The day after, both Firefly- and Renilla-luciferase activities were quantified using the Dual-Glo Luciferase Assay System (Promega, Madison, WI, USA) according to the manufacturer's instructions. Luminescence was detected using a PHERAstar Plus plate reader (BMG Labtech, Ortenberg, Germany). The measured luminescence for Firefly-luciferase activity was normalised to that of Renilla luciferase.

mRNA and protein stability. Cells were transfected with siRNA oligonucleotides as before. Forty-eight hours after transfection cells were treated with $5 \mu \mathrm{g} / \mathrm{ml}$ actinomycin D for $1-4 \mathrm{~h}$. Subsequently, RNA was isolated using an RNeasy Mini Kit (Qiagen) following the manufacturer's instructions. Gene expression analysis was performed by qPCR as described before, using HPRT and GAPDH as housekeeping genes. For protein stability, cells were incubated with $\mathrm{CHX}$ for 2,4 or $6 \mathrm{~h}$ and protein measured by SDS-PAGE/qWB using the Fusion SOLO quantitative luminescence system (PEQLAB, Erlangen, Germany).

Statistical analysis. Mean \pm S.E.M. of three independent experiments were calculated. Statistical tests were carried out as indicated in each figure legend using GraphPad Prism (GraphPad Software Inc., San Diego, CA, USA).

\section{Conflict of Interest}

The authors declare no conflict of interest.

Acknowledgements. We are grateful to Dr. Spencer Gibson (University of Manitoba, USA) for wild-type and NF- $\kappa$ B-mt DR5-luciferase constructs, Dr. Ingram laccarino (Institute of Human Genetics, University Hospital Schleswig-Holstein, Kiel, Germany) for the BCL- $X_{L}$ expression vector and to Andrew M. Smart for many very fruitful discussions. Within Imperial College London, we are indebted to Dr. Charlotte Bevan, her research team and Dr. Olivier Pardo for helpful discussions, and Dr. Anna Maria Tommasi for technical help. Cancer Research UK funded CRS and APC-P (C37990/A12991) at the Imperial Cancer Research UK Centre, and also AVF and APC-P (CA5775); CEM was funded by MRC and Johnson \& Johnson (CASE studentship G1000390); MBM was funded by the ERASMUS programme through a student mobility placement studentship (DE-2013-ERA/MOB-KonsZuV01-CP6); CRS, AVF, CRC, MJS and APC-P were additionally funded by Cancer Treatment and Research Trust (CTRT) and APC-P is the recipient of an Elsie Widdowson Fellowship. The funders had no role in study design, data collection and analysis, decision to publish or preparation of the manuscript.

\section{Author contributions}

APC-P and CRS designed the study and wrote the manuscript; CRS, AVF, SST, $M L G, M B M$ and CEM conducted the experiments; all authors analysed the data and commented on the manuscript.

1. Wiley SR, Schooley K, Smolak PJ, Din WS, Huang CP, Nicholl JK et al. Identification and characterization of a new member of the TNF family that induces apoptosis. Immunity 1995; 3: 673-682.

2. Pitti RM, Marsters SA, Ruppert S, Donahue CJ, Moore A, Ashkenazi A. Induction of apoptosis by Apo-2 ligand, a new member of the tumor necrosis factor cytokine family. J Biol Chem 1996; 271: 12687-12690.

3. Falschlehner C, Ganten TM, Koschny R, Schaefer U, Walczak H. TRAIL and other TRAIL receptor agonists as novel cancer therapeutics. Adv Exp Med Biol 2009; 647: 195-206.

4. Walczak H, Miller RE, Ariail K, Gliniak B, Griffith TS, Kubin M et al. Tumoricidal activity of tumor necrosis factor-related apoptosis-inducing ligand in vivo. Nat Med 1999; 5: 157-163.

5. Walczak H, Degli-Esposti MA, Johnson RS, Smolak PJ, Waugh JY, Boiani N et al. TRAILR2: a novel apoptosis-mediating receptor for TRAIL. EMBO J 1997; 16: 5386-5397.

6. Pan G, O'Rourke K, Chinnaiyan AM, Gentz R, Ebner R, Ni J et al. The receptor for the cytotoxic ligand TRAIL. Science 1997; 276: 111-113.

7. Gonzalvez F, Ashkenazi A. New insights into apoptosis signaling by Apo2L/TRAIL. Oncogene 2010; 29: 4752-4765.

8. Screaton GR, Mongkolsapaya J, Xu XN, Cowper AE, McMichael AJ, JI Bell. TRICK2 a new alternatively spliced receptor that transduces the cytotoxic signal from TRAlL. Curr Biol 1997; 7: 693-696.
9. Mellier G, Huang S, Shenoy K, Pervaiz S. TRAILing death in cancer. Mol Aspects Med 2010; 31: 93-112.

10. Bialik S, Kimchi A. The death-associated protein kinases: structure, function, and beyond. Annu Rev Biochemis 2006; 75: 189-210.

11. Raval A, Tanner SM, Byrd JC, Angerman EB, Perko JD, Chen SS et al. Downregulation of death-associated protein kinase 1 (DAPK1) in chronic lymphocytic leukemia. Cell 2007; 129: 879-890

12. Kawai T, Nomura F, Hoshino K, Copeland NG, Gilbert DJ, Jenkins NA et al. Death-associated protein kinase 2 is a new calcium/calmodulin-dependent protein kinase that signals apoptosis through its catalytic activity. Oncogene 1999; 18: 3471-3480.

13. Inbal B, Shani G, Cohen O, Kissil JL, Kimchi A. Death-associated protein kinase-related protein 1, a novel serine/threonine kinase involved in apoptosis. Mol Cell Biol 2000; 20: 1044-1054.

14. Inbal B, Bialik S, Sabanay I, Shani G, Kimchi A. DAP kinase and DRP-1 mediate membrane blebbing and the formation of autophagic vesicles during programmed cell death. J Cell Biol 2002; 157: 455-468.

15. Bonito NA, Drechsler J, Stoecker S, Carmo CR, Seckl MJ, Hermanns HM et al. Control of gp130 expression by the mitogen-activated protein kinase ERK2. Oncogene 2014; 33: 2255-2263.

16. Watling D, Carmo CR, Kerr IM, Costa-Pereira AP. Multiple kinases in the interferon-gamma response. Proc Natl Acad Sci USA 2008; 105: 6051-6056.

17. Degli-Esposti MA, Smolak PJ, Walczak H, Waugh J, Huang CP, DuBose RF et al. Cloning and characterization of TRAIL-R3, a novel member of the emerging TRAIL receptor family. J Exp Med 1997; 186: 1165-1170.

18. Emery JG, McDonnell P, Burke MB, Deen KC, Lyn S, Silverman $C$ et al. Osteoprotegerin is a receptor for the cytotoxic ligand TRAIL. J Biol Chem 1998; 273: 14363-14367.

19. Shetty S, Graham BA, Brown JG, Hu X, Vegh-Yarema N, Harding G et al. Transcription factor NF-kappaB differentially regulates death receptor 5 expression involving histone deacetylase 1. Mol Cell Biol 2005; 25: 5404-5416.

20. Ganten TM, Haas TL, Sykora J, Stahl H, Sprick MR, Fas SC et al. Enhanced caspase-8 recruitment to and activation at the DISC is critical for sensitisation of human hepatocellular carcinoma cells to TRAIL-induced apoptosis by chemotherapeutic drugs. Cell Death Differen 2004; 11(Suppl 1): S86-S96.

21. Sinicrope FA, Penington RC, Tang XM. Tumor necrosis factor-related apoptosis-inducing ligand-induced apoptosis is inhibited by Bcl-2 but restored by the small molecule Bcl-2 inhibitor, HA 14-1, in human colon cancer cells. Clin Cancer Res 2004; 10 8284-8292.

22. Huang S, Sinicrope FA. BH3 mimetic ABT-737 potentiates TRAIL-mediated apoptotic signaling by unsequestering Bim and Bak in human pancreatic cancer cells. Cancer Res 2008; 68: 2944-2951.

23. Kandasamy K, Kraft AS. Proteasome inhibitor PS-341 (VELCADE) induces stabilization of the TRAIL receptor DR5 mRNA through the 3'-untranslated region. Mol Cancer Therap 2008; 7: 1091-1100.

24. Mendoza FJ, Ishdorj G, Hu X, Gibson SB. Death receptor-4 (DR4) expression is regulated by transcription factor NF-kappaB in response to etoposide treatment. Apoptosis 2008; 13: 756-770.

25. Bernard D, Quatannens B, Vandenbunder B, Abbadie C. Rel/NF-kappaB transcription factors protect against tumor necrosis factor (TNF)-related apoptosis-inducing ligand (TRAIL)-induced apoptosis by up-regulating the TRAIL decoy receptor DcR1. J Biol Chem 2001; 276: 27322-27328.

26. Zender L, Hutker S, Mundt B, Waltemathe M, Klein C, Trautwein C et al. NFkappaB-mediated upregulation of bcl-xl restrains TRAIL-mediated apoptosis in murine viral hepatitis. Hepatology 2005; 41: 280-288.

27. Degli-Esposti MA, Dougall WC, Smolak PJ, Waugh JY, Smith CA, Goodwin RG. The novel receptor TRAIL-R4 induces NF-kappaB and protects against TRAILmediated apoptosis, yet retains an incomplete death domain. Immunity 1997; 7 : 813-820.

28. Tergaonkar V. NFkappaB pathway: a good signaling paradigm and therapeutic target. Int J Bioch Cell Biol 2006; 38: 1647-1653.

29. Yoo HJ, Byun HJ, Kim BR, Lee KH, Park SY, Rho SB. DAPk1 inhibits NF-kappaB activation through TNF-alpha and INF-gamma-induced apoptosis. Cell Signal 2012; 24: 1471-1477.

30. Chuang YT, Fang LW, Lin-Feng MH, Chen RH, Lai MZ. The tumor suppressor deathassociated protein kinase targets to TCR-stimulated NF-kappa B activation. J Immunol 2008; 180: 3238-3249.

31. Gozuacik D, Kimchi A. DAPk protein family and cancer. Autophagy 2006; 2: 74-79.

32. Sprick MR, Weigand MA, Rieser E, Rauch CT, Juo P, Blenis J et al. FADD/MORT1 and caspase- 8 are recruited to TRAIL receptors 1 and 2 and are essential for apoptosis mediated by TRAIL receptor 2. Immunity 2000; 12: 599-609. 